\title{
Tecnologías para remoción de siloxanos en biogás
}

\author{
Sandra Pioquinto García, ${ }^{1}$ Nancy Elizabeth Dávila Guzmán, ${ }^{1}$ Luis Ángel Garza Rodríguez, ${ }^{2,3}$ Felipe de \\ Jesús Cerino Córdova', Eduardo Soto Regalado', Diana Bustos Martínez', Victor Manuel Ovando Medina ${ }^{4}$. \\ ${ }^{1}$ Universidad Autónoma de Nuevo León, Facultad de Ciencias Químicas, \\ ${ }^{2}$ Universidad Regiomontana, Departamento de Ingeniería Quimica \\ ${ }^{3}$ Consorcio Educativo Internacional Warden, Av. Constitución 2233 Pte. Col. Obispado., Monterrey, N.L., México C.P. 6400 \\ ${ }^{4}$ Universidad Autónoma de San Luis Potosí, Coordinación Académica Región Altiplano, Departamento de Ingeniería Química. \\ nancy.davilagz@uanl.edu.mx
}

\section{Resumen}

El biogás es purificado para satisfacer los requisitos en las diferentes aplicaciones del gas (motores, calderas, vehículos, etc.), para aumentar el poder calorífico y para estandarizar la calidad del mismo. Los principales contaminantes del biogás son dióxido de carbono, ácido sulfhídrico, vapor de agua, oxígeno, nitrógeno y partículas de silicio. Las partículas de silicio, toman importancia ya que se depositan en forma de microcristales de silicio en diferentes partes del motor de combustión y ocasionan su deterioro, por lo que se hace necesario el remplazo de la parte afectada generando un alto costo por concepto de mantenimiento. El presente trabajo tiene como finalidad explicar las técnicas de purificación de biogás y más a detalle ofrecer un panorama general de los siloxanos y siloxanos y las técnicas que se han estudiado para su remoción.

Palabras clave: Energía, biogás, ambiente, siloxanos, tecnología.

\section{Abstract}

Biogas is purified to meet the requirements of different gas applications (engines, boilers, vehicles, etc.), to increase the calorific value and to standardize quality. The main pollutants of biogas are carbon dioxide, hydrogen sulfide, water vapor, oxygen, nitrogen and silicon particles. The silicon particles are important because they are deposited in the form of silicon microcrystals in different parts of the engine and cause their deterioration, so that it is necessary to replace the affected part which generates a high cost due to maintenance operations. The present work aims to explain the biogas purification techniques and more in detail to provide an overview of the siloxanes and the techniques that have been studied for their removal.

\section{Keywords: Energy, biogás, environmental, siloxane, technologies}

\section{Introducción}

La energía se define como la capacidad de hacer trabajo, de producir movimiento y de generar algún cambio. Es parte de la naturaleza de todo sistema físico y hay diferentes maneras en las que la energía puede ser convertida, usada, almacenada, y transferida para su uso.

Los seres humanos, a lo largo de la historia, han aprendido a desarrollar sistemas de vida en los que, además de suministrar la energía necesaria para su subsistencia, (necesidades básicas de alimentación, vivienda, protección, etc.), producen energía para progresar y mantener un estilo de vida más cómodo y de mejor calidad (implementación de dispositivos electrónicos de comunicación, tecnologías de la información, transporte, etc.) y para esto, han recurrido a fuentes de energía muy variadas, desde el uso de los combustibles fósiles (petróleo, gas y carbón) hasta el aprovechamiento de la energía solar, eólica, hidráulica y nuclear.

Desde la era industrial, los combustibles fósiles y sus tecnologías han sido las principales fuentes de energía para la humanidad, sin embargo, por sus características técnicas y el crecimiento en su consumo han generado una serie de amenazas para la salud, la estabilidad económica y el equilibrio con el ambiente.

Por ejemplo, la emisión de gases de efecto invernadero ha propiciado un cambio en el clima y por lo tanto esto ha obligado a generar medidas de adaptación y mitigación entre los habitantes del planeta. Por lo anterior, el principal mecanismo de defensa ante estos cambios es hacer un uso racional de la energía en todas sus formas, progresando hacia un modelo energético con nuevas formas de aprovechamiento de energías más eficientes. Estas nuevas formas incluyen las fuentes de energía alternativas o renovables.

Las fuentes de energía renovables se distribuyen más uniformemente que las que provienen de los recursos fósiles y nucleares en la tierra. El beneficio más importante de los sistemas de energía renovable es la disminución de la contaminación ambiental. Algunas de las energías alternativas son: energía solar, energía eólica, energía geotérmica, energía mareomotriz y la energía de biomasa[1]. En este sentido, la biomasa representa sólo el $3 \%$ del consumo de energía primaria en los países industrializados. Sin embargo, en gran parte de la población rural de los países en desarrollo (que representa alrededor del $50 \%$ de la población mundial), depende de la biomasa, principalmente de la madera para combustible[2].

En la Figura 1, se muestra el uso actual de las energías renovables y sus proyecciones hasta el año 2040[3]. Se puede observar que para las próximas décadas habrá un marcado crecimiento en el aprovechamiento de todas las energías renovables, tanto que el Consejo Europeo de Energías Renovables (EREC) estima que para el año 2040 , casi la mitad de la energía global provendrá de las fuentes de energía renovable. La biomasa es la fuente de energía renovable más utilizada, seguida de la geotérmica y la hidroeléctrica. 


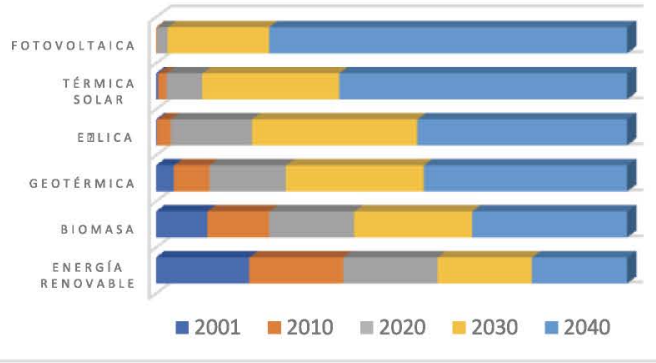

Figura1.Escenarioglobaldeenergíarenovable,2001-2040

Paralospróximosaños,seesperaquelosprincipalesprocesos con biomasa puedan mejorar en dos aspectos, primero en la combustióneficientedelosresiduos, desechosybagazopara generar calor y electricidad y, segundo en el incremento de cultivos energéticos para la producción de bioetanol, biodieselyotrosbiocombustibles.

En general, el uso de biomasa no es en sí mismo motivo de preocupación, cabemencionarquelas tecnologías y elcosto degeneración de energía y calor por biomasa dependen dela materia primay su disponibilidad, así comodel tamaño dela planta de generación y del sistema de aprovechamiento de energía, sin embargo, cuando las tecnologías de aprovechamiento de energía son ineficaces hay consecuencias adversas al ambiente y a la economía.

Por otro lado, los biocombustibles representan una opción sustentable para satisfacer una parte de las necesidades energéticas de la humanidad, además producen energía emitiendo bajos niveles de dióxido de carbono $\left(\mathrm{CO}_{2}\right)$, promueven el desarrollo regional, fortalecen la estructura socialyaseguranelsuministroporunlargoperíododetiempo. Estas características resultan ser atractivas hoy en día para quelosbiocombustibles puedan sustituir a los combustibles fósiles.

Dentro de los biocombustibles, se encuentra el biogás, producido por la degradación bacteriana de la biomasa en condiciones anaeróbicas ya sea en medios naturales o de forma tecnificada en dispositivos especiales llamados biodigestores. Los biodigestores son sistemas anóxicos en losquesedegradalamateriaorgánicadebidoalaactividadde microorganismos y el control de otros factores como la temperatura, $\mathrm{pH}$ y nutrientes[4]. En general, los elementos básicos de la producción tecnificada de biogás son: materia prima, el biodigestor y los productos (biogás y abono orgánico).

El biogás consiste en una mezcla típica de metano $\left(\mathrm{CH}_{4}\right)$, dióxido de carbono $\left(\mathrm{CO}_{2}\right)$ y una cantidad menor de varios compuestos residuales como vapor de agua, sulfuro de hidrógeno $\left(\mathrm{H}_{2} \mathrm{~S}\right)$, benceno, tolueno, amoníaco $\left(\mathrm{NH}_{3}\right)$, compuestos de silicio (COV - Si) y mercaptanos, estos últimos reúnen menos del $6 \%$ de la composición total del biogás[5]. La composición porcentual del biogás varía dependiendo del sistema que lo genere. En la Figura 2, se muestralacomposición debiogás generadoenunvertedero, en una planta de tratamiento de aguas residuales y en un digestorcomún.

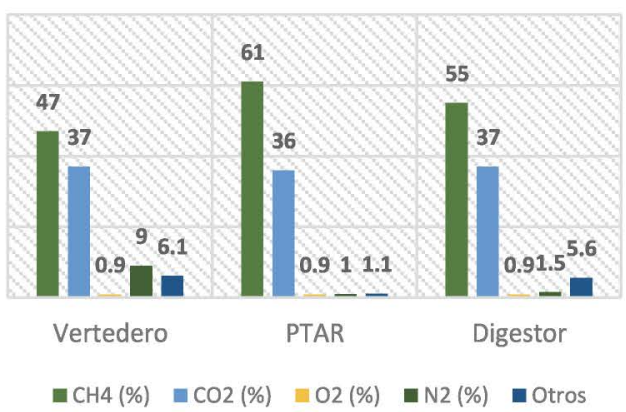

Figura2. Promedio de la composición química del biogás [6].

Antes de que el biogás pueda ser aprovechado para la generación de electricidad, éste debe ser sometido a un proceso de purificación por el cual se eliminan aquellas componentes que podrían dañar la eficiencia del equipo, específicamentedelmotorodelaturbina.Acontinuación, se explican a detalle los principales contaminantes del biogás y sus métodos de remoción más utilizados.

\section{Contaminantes}

Se sabe que el biogás puede contener algunas impurezas y elementos traza que deben ser removidos antes de su uso en la matriz energética. La remoción de $\mathrm{CO}_{2}, \mathrm{H}_{2} \mathrm{~S}$, vapor de agua, nitrógeno y oxígeno del biogás, permiten obtener biometano con una concentración de gas metano superior al $95 \%$, con lo cual aumenta su poder calorífico[7].

Dióxido de carbono. - La eliminación del dióxido de carbono $\left(\mathrm{CO}_{2}\right)$ aumenta el poder calorífico del biogás y mejora su calidad, similar al del gas natural. Hay diversos métodos de remoción, los más comunes que se realizan son la absorción, adsorción, separación criogénica, separación por membrana, entre otras.

En los procesos de absorción, el $\mathrm{CO}_{2}$ es removido debido a la alta polaridad de la molécula. El agua es el solvente más común para la purificación del biogás, el diseño del sistema depende de la solubilidad del dióxido de carbono ya que la solubilidad se rige por la presión, la temperatura y el $\mathrm{pH}$, de tal forma que cuando la presión aumenta, la solubilidad del $\mathrm{CO}_{2}$ en agua aumenta, pero disminuye cuando se incrementa la temperatura.

También para la eliminación de $\mathrm{CO}_{2}$ se utilizan solventes orgánicos como el polietilenglicol (selexol, genosorb) y las aminas (monoetanolamina o dietanolamina), donde se emplea una baja presión, el producto químico se regenera con vapor.

La adsorción de dióxido de carbono puede ser a través de sólidos como carbón activado o tamices moleculares. Este mecanismo es un proceso de fácil diseño $\mathrm{y}$ operación, pero es costoso por el uso de altas presiones y elevados requerimientos de calor. La desorción es realizada por despresurización o utilizando un leve vacío. 
Agua. - El biogás que sale del digestor siempre se encuentra saturado de agua. La concentración de agua en el biogás depende de la presión y de la temperatura dentro del digestor. El agua en el biogás puede causar problemas como la corrosión en tuberías; también, disminuye el contenido energético del gas $\mathrm{y}$, por lo tanto, puede afectar el uso final del mismo.

El agua puede ser removida por congelamiento, compresión, absorción y adsorción. Al incrementar la presión o disminuir la temperatura, el agua se condensa y se puede eliminar del biogás; la remoción por adsorción se puede hacer usando dióxido de silicio, carbón activado o tamices moleculares que después de cierto tiempo, se regeneran por calor o por diferencia de presión; finalmente la remoción de agua también puede ser por absorción con soluciones de glicol o con soluciones higroscópicas[8].

Sulfuro de hidrógeno. - El elemento más perjudicial, en el aprovechamiento del biogás, para la generación de electricidad es el sulfuro de hidrógeno $\left(\mathrm{H}_{2} \mathrm{~S}\right)$ [7]. Otras impurezas que contienen azufre también pueden estar presentes en el biogás, pero el $\mathrm{H}_{2} \mathrm{~S}$ es el más común. El $\mathrm{H}_{2} \mathrm{~S}$ es formado por bacterias que tienen la capacidad de reducir el ion sulfato presente en el digestor a sulfuro de hidrógeno. Estas bacterias están presentes en el digestor y compiten con bacterias formadoras de metano para el mismo sustrato, pero, en lugar de formar biogás, se forma sulfuro de hidrógeno [].

Si el $\mathrm{H}_{2} \mathrm{~S}$ no se elimina de la corriente de biogás y se desea generar energía eléctrica puede causar corrosión al motor de las partes metálicas por la emisión de $\mathrm{SO}_{2}$ de la combustión, especialmente cuando el motor no funciona continuamente. También es importante tener en cuenta que el $\mathrm{H}_{2} \mathrm{~S}$ es altamente tóxico y puede resultar en graves riesgos para la salud.

La concentración de sulfuro de hidrógeno puede disminuir en el biogás por: precipitación en el digestor, tratamiento del gas donde se usen materiales adsorbentes como carbón activado; sustancias químicas absorbentes como el hidróxido de sodio y las soluciones de quelato férrico y tratamiento biológico donde microorganismos como las especies Thiobacillus y Sulfolobus oxidan el $\mathrm{H}_{2} \mathrm{~S}[8]$. Otra tecnología, ampliamente utilizada es la esponja de hierro, que consiste en un tanque cilíndrico entre el digestor y el sistema de utilización de biogás, el óxido de hierro utilizado se regenera con aire y puede utilizarse otras 3 o 4 veces y cuando se ha gastado, puede quemarse, confinarse o esparcirse en campos agrícolas[9].

Oxígeno y nitrógeno. - Dado que el biogás se forma en condiciones anaeróbicas, ni el oxígeno ni el nitrógeno están generalmente presentes en el biogás, pero sí se pueden encontrar si se permite que el aire entre en algún lugar del sistema, a veces el aire se añade conscientemente al proceso para reducir el sulfuro de hidrógeno como una forma de limpiar el biogás, asimismo el nitrógeno en el biogás puede ser signo de fuga de aire en el digestor. El oxígeno puede conducir a la formación de mezclas inflamables con el metano del biogás, así que el oxígeno tiene que ser controlado cuidadosamente. Algunas tecnologías de reducción de oxígeno y nitrógeno en el biogás consisten en usar materiales adsorbentes como carbón activado, tamices moleculares y membranas.

Como se puede observar, las técnicas de remoción, simultáneamente, podrían remover más de una sola impureza.

\section{Compuestos Orgánicos Volátiles de Silicio: Siloxanos}

Un caso particular en la purificación del biogás es el estudio de los siloxanos. Los siloxanos son compuestos usados en productos tales como retardantes de fuego, shampoo, cosméticos y medicamentos, impregnantes de materiales para la construcción, productos de limpieza, aceites hidráulicos, desodorantes, textiles, etc. Los siloxanos son moléculas que están compuestas por unidades de $\mathrm{R}_{2} \mathrm{SiO}$, en las que $\mathrm{R}$ es un hidrógeno o un radical hidrocarbonado.

Si los siloxanos están presentes en el sustrato que entra en el digestor, estos compuestos también se encontrarán en pequeñas cantidades en el biogás producido, debido al hecho de que algunos de estos compuestos se evaporan. La temperatura en el digestor determina la cantidad de siloxanos que acarrea el biogás debido a que los siloxanos de bajo peso molecular presentan una mayor presión de vapor por lo que se evaporan con mayor facilidad.

Los siloxanos obstaculizan el uso del biogás para fines de aprovechamiento de energía, puesto que se transforman en silicatos y cuarzo microcristalino que se acumulan en los motores, disminuyen el volumen de la cámara de combustión y contribuyen en general a la abrasión del interior del motor.

La presencia de partículas de sílice, en las componentes del motor, ocasiona un aumento de la fricción metálica y por ende el fallo de varios elementos mecánicos. También, el desgaste generado se traduce en un aumento del consumo de aceite[10]. En la Figura 3, se observa que el punto de mayor desgaste en el sistema, ocurre precisamente en el punto en que hay mayor concentración de silicio al interior del motor, a las 2500 horas de uso de la máquina, el desgaste es mínimo junto con la cantidad de silicio, pero se observa que, en ese mismo punto, es donde se consume mayor cantidad de aceite para el motor.

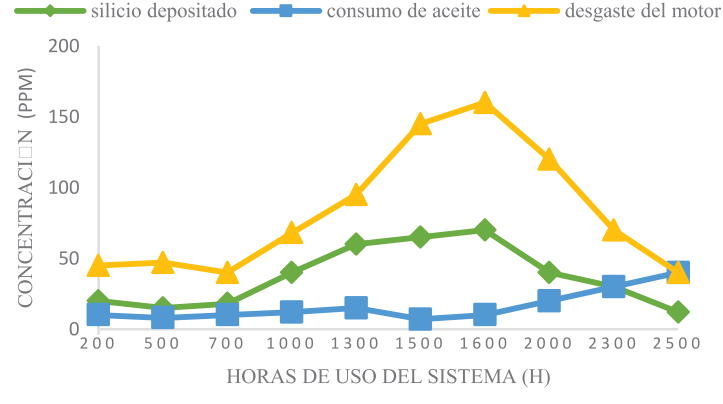

Figura 3. Desgaste y consumo de aceite en función de la concentración de siloxanos. 
Expuesto lo anterior, se sugiere una concentración de siloxanos en el biogás que varía de acuerdo a sus aplicaciones. Por ejemplo, los fabricantes de motores a gas para el suministro de biogás[11], recomiendan limitar el contenido de siloxanos entre $10-50 \mathrm{mg} \mathrm{m}^{-3}$; para los sistemas de calefacción y energía, se sugiere una concentración límite de siloxanos de $0.2 \mathrm{mg} \mathrm{m}^{-3} \mathrm{y}$, para motores de combustión[12] de vehículos y turbinas, entre $5-10 \mathrm{mg} \mathrm{m}^{-3}$.

Los siloxanos que se encuentran principalmente en el b i o g á $\mathrm{s}$ $\mathrm{s}$ o $\mathrm{n}$ : hexametildisiloxano (L2), octametiltrisiloxano (L3), decametiltetrasiloxano (L4), dodecametilpenta siloxano (L5), hexametilciclotrisiloxano (D3), octametil ciclotetrasiloxano (D4), decametilciclopentasiloxano(D 5) y dodeca-metilciclohexasiloxano (D6). De estos, el D4 es el siloxano presente en mayor proporción (64 \%) en el biogás de digestión y el segundo (17\%) en el biogás de rellenos sanitarios[13]. La tecnología disponible para la remoción de siloxanos incluye: criogenia, biofiltración, degradación ácida, absorción, adsorción, entre otros. A continuación, se describe cada uno de estos.

\section{Adsorción}

La adsorción es el fenómeno de acumulación o retención de átomos, moléculas o especies en la superficie de un material. Al átomo, molécula o especie se le conoce como adsorbato y al material en el que se retiene, se le conoce como adsorbente. El proceso de adsorción de siloxanos, depende de la atracción física de la molécula y la superficie interna o externa del material adsorbente, cabe mencionar que la accesibilidad de las moléculas de siloxanos al interior del material dependerá del tamaño de poro del adsorbente[14].

Los materiales adsorbentes se colocan en columnas con dimensiones acordes a las capacidades de adsorción y también con base en la concentración de siloxanos en el fluido. La capacidad de adsorción de los materiales poco a poco disminuye ya que los sitios son ocupados, en principio, por los siloxanos. El tiempo máximo que se puede emplear el material adsorbente sin que cause problemas está dado por el tiempo de ruptura, de omitir este concepto, la concentración de siloxanos en el biogás podría incrementarse[15].

La ventaja de trabajar con un material adsorbente es que puede ser eficiente y asequible, por ejemplo, los más comercializados han sido el carbón activado de origen mineral y el gel de sílice. La desventaja de esta tecnología es que se requiere constantemente del reemplazo del material adsorbente. En particular, el carbón activado requiere de altas temperaturas para su regeneración (600 $\left.1000^{\circ} \mathrm{C}\right)[16,17]$ y el gel de sílice resulta poco conveniente cuando el biogás es húmedo[18].

Adicionalmente, otros materiales adsorbentes utilizados para la remoción de siloxanos son las zeolitas, la alúmina y los tamices moleculares. Sin embargo, estos últimos presentes menores eficiencias de remoción por lo que su aplicación en niveles industriales es limitada $[19,20]$.

\section{Absorción}

El proceso de absorción gas - líquido consiste en la transferencia de contaminantes de la fase gaseosa al líquido absorbente. El líquido absorbente es un solvente orgánico a altas temperaturas. Dicho proceso se lleva a cabo en una columna empacada en el que a flujo contracorriente hay contacto entre el gas y la solución absorbente. La eficiencia del proceso depende del área superficial del empaque, el tiempo de contacto y la solubilidad de los contaminantes en la solución absorbente.

La absorción se aplica para la eliminación de siloxanos, porque los siloxanos son destruidos por sustancias ácidas y bases fuertes que implican valores de $\mathrm{pH}$ bajos o altos, respectivamente. Cabe señalar que la aplicación potencial de estos agentes se reduce debido a la poca seguridad y alta corrosión. Además, sólo se pueden utilizar ácidos líquidos ya que las bases líquidas forman carbonatos que precipitan sobre el equipo. Los ácidos más utilizados han sido ácido nítrico, ácido sulfúrico y ácido fosfórico [21,15].

Una desventaja de trabajar con ácido sulfúrico es que genera trazas que pudieran entrar en el motor de combustión y corroerlo. Al trabajar con ácido nítrico, se requiere de una baja concentración para alcanzar el 95 $\%$ de remoción de siloxanos, la temperatura óptima es cercana a los $60{ }^{\circ} \mathrm{C}$. También se han evaluado el tetradecano y algún tipo de aceite de hidrocarburo[22].

\section{Criogenia}

Este método es sencillo y puede ser usado para remover siloxanos y agua. Consiste en la condensación de los compuestos presentes en el biogás por bajas temperaturas y por la reducción de la presión. Lo que dificulta su uso es el alto costo debido al alto consumo de energía, la ventaja es que esta es una tecnología que no es tóxica y que no requiere de la eliminación de sus agentes como en el caso de la adsorción. El equipo consiste básicamente en un intercambiador de calor o una cámara de enfriamiento donde se hace circular un gas comprimido por un sistema de bobina lleno de refrigerante que se bombea y se recicla desde un refrigerador.

Este mecanismo es usado como un pretratamiento del biogás, seguido de alguna otra tecnología, ya que no es lo suficientemente eficaz: sólo el $26 \%$ de los siloxanos se condensa a $-25^{\circ} \mathrm{C}$ y el $99 \%$ de la retención de los siloxanos se alcanza a los $-70.0^{\circ} \mathrm{C}$ [23]. Sin embargo, mucho depende de la concentración máxima de siloxanos en el biogás. Entre más volátil sea el siloxano, más difícil será que se condense, es así que los siloxanos L2, L3 y D3 sean difíciles de reducir a concentraciones inferiores a las presentes en el biogás. Por otro lado, los siloxanos D4, D5 y L4, a temperaturas entre $55^{\circ} \mathrm{C}$ y 70 ${ }^{\circ} \mathrm{C}$, se reducen a concentraciones aceptables, por debajo de $1 \mathrm{mg} / \mathrm{Nm}^{3}$.

\section{Remoción Biológica}

La remoción de contaminantes por procesos biológicos es un fenómeno que ocurre en una biopelícula y depende 
de la transferencia de los contaminantes de la fase gas a la fase líquida. Este mecanismo se rige por la solubilidad del contaminante en el agua y, por lo tanto, la aplicación de los procesos biológicos en la remoción de siloxanos podría verse limitada por la baja solubilidad de los siloxanos en el agua. Sin embargo, algunos microorganismos son capaces de generar biosurfactantes y de esta manera aumentar la solubilidad de los compuestos, haciendo los procesos de remoción biológica una opción para la remoción eficiente.

Otra manera de remover siloxanos puede ser usando enzimas específicas como la silicasa. Aunque también se han estudiado colonias de microorganismos que incluyen Pseudomonas (P. aeruginoasa, P. fluorescens, P. Putida), Agrobacterium (A. radiobacter), Arthrobacter, Fusarium oxysporium (un hongo), rhodanobacter, zooglea, mesorhizobium y xanthomonadacea. Varios de los microorganismos, tienen potencial para la eliminación anaeróbica de siloxanos usando como aceptor de electrones algún otro elemento diferente al oxígeno, por ejemplo el nitrato[24].

Para la purificación del biogás, se utilizan biorreactores como bioscrubbers (BS), biofiltros (BF) y una combinación de estos, conocidos como filtros biotrickling (BTF). En estos sistemas, el mecanismo principal para la remoción de siloxanos es la transformación bioquímica. La biodegradación de siloxano puede generar productos como dimetilsilanodiol (DMSD), ácido silícico, agua y dióxido de carbono. El DMSD, posteriormente puede ser retenido sobre adsorbentes[14].

La biodegradabilidad de los compuestos de silicio, está en función de su peso molecular, si el peso molecular es alto, como el polidimetilsiloxano, es más biodegradable. Por el contrario, un compuesto de bajo peso molecular, como el decametiltetrasiloxano, es menos biodegradable. En general, las pruebas de biodegradación son difíciles de realizar debido a su baja solubilidad y alta velocidad de vaporización[24].

Por otra parte, el uso de algún mecanismo de remoción biológica, también puede resultar favorable en el tratamiento de sulfuro de hidrógeno para el control de olores. Los filtros biotrickling han sido probados en la remoción de sulfuro de hidrógeno bajo condiciones anóxicas y pueden ser una alternativa para remover siloxanos pero simultáneamente también remover sulfuro de hidrógeno[14].

\section{Membranas}

Las membranas son láminas muy finas con un espesor en el intervalo de 0.2 a $2.0 \mu \mathrm{m}$ y su volumen es muy pequeño a comparación de otros materiales de remoción de siloxanos. Las membranas pueden ser poliméricas o inorgánicas y se caracterizan por tener una elevada área superficial en tan poco volumen, ventaja que tienen en comparación con otros materiales de separación que son más grandes y que pueden contribuir a mayores costos de operación.

La permeabilidad y selectividad de una membrana hacia cierta molécula depende del tamaño de poro y de las interacciones moleculares. Al respecto de la regeneración, las membranas se hacen pasar por un proceso de purga de

los contaminantes con un gas inerte o un disolvente. De esta manera el tiempo de vida de una membrana es de aproximadamente 3 años.

Un sistema de membranas resulta ser una opción en la purificación del biogás, pero se requieren de presiones altas para que el gas pase por la membrana (36 bar) o bien, un sistema de membranas a bajas presiones para que las moléculas se separen por difusión a través de una membrana microporosa hidrofóbica.

Es necesario que el biogás antes de ser pasado por el sistema de membranas, sea previamente tratado, ya que otras impurezas propias del biogás (sulfuro de hidrógeno, amoníaco, etc.) y del sistema (vapores de aceite de los compresores) podrían dañar la membrana. La tecnología por membrana para la separación de impurezas en el biogás funciona bien hasta el punto en que la membrana se sature y entonces se bloqueen los poros o se ensucie. Es entonces cuando disminuye la eficiencia de separación.

\section{Conclusiones}

Las tecnologías para procesos de purificación de biogás tienen una eficiencia variable, en el que su aplicación dependerá de la concentración de contaminantes en el biogás, inclusive, se pueden combinar 2 o más técnicas dependiendo de las facilidades económicas y simplicidad del sistema.

Es necesario señalar que, en la remoción de siloxanos, algunas técnicas aún se encuentran en fase de pruebas de laboratorio, como la degradación y la biofiltración. El proceso de adsorción es la tecnología con mayor eficiencia en la remoción de siloxanos de biogás, siendo el carbón activado el material adsorbente más ampliamente utilizado por su bajo costo, fácil adquisición y porque es un material multiadsorbente. Sin embargo, la regeneración del carbón activado representa un reto energético en la purificación de biogás, debido a las altas temperaturas requeridas para este proceso. Es por ello, que las investigaciones actuales se han centrado en el estudio de nuevos materiales para la remoción de siloxanos que puedan ser regenerados a menor temperatura sin perder su eficiencia de remoción.

\section{Referencias}

Mendeli, D. Energía

http://www.cricyt.edu.ar/enciclopedia/termi nos/Energ.htm (accessed Feb 3, 2017).

Boyle, G.; Open University. Renewable energy : power for a sustainable future.

Demirbas, A. Energy Sources, Part B 2009, $4,212-224$.

Servicios manufactureros alcoholes industriales. 2003; pp 1-22.

Petr, D.; Vasclav, P.; Zuzana, S.; Véra, J.; Jirí, V.; Elisa, E.; Carolus, J. J.; Pavel, I. Sep. Purif. Technol. 2014, 131, 108-116. 
[7] Varnero, M. T.; Carú, M.; Galleguillos, K.; Achondo, P. Inf. tecnológica 2012, 23 (2), 31- 40 .

[8] Petersson Arthur WeLLInGer, A.; rudolf BrAUn, A.; Andrew, C. 2009.

[9] California Energy Conmission; University of California, D. 2015.

[10] Aranzabe, E.; Ciria, J. I. 2004.

[11] Zamorska-Wojdyła, D.; Gaj, K.; Hołtra, A.; Sitarska, M. Ecol. Chem. Eng. S 2012, 19 (1), 77-87.

[12] Muñoz, R.; Meier, L.; Diaz, I.; Jeison, D. Rev. Environ. Sci. Biotechnol. 2015, 14 (4), 727-759.

[13] Tansel, B.; Surita, S. C. Waste Manag. 2014, 34 (11), 2271-2277.

[14] Soreanu, G.; Béland, M.; Falletta, P.; Edmonson, K.; Svoboda, L.; Al-Jamal, M.; Seto, P. Can. Biosyst. Eng. / Le Genie des Biosyst. au Canada 2011, 53.

[15] Schweigkofler, M.; Niessner, R. J. Hazard. Mater. 2001, 83 (3), 183-196.

[16] Montanari, T.; Finocchio, E.; Bozzano, I.; Garuti, G.; Giordano, A.; Pistarino, C.; Busca, G. Chem. Eng. J. 2010, 165 (3), 859-863.

[17] Universidad de Alicante. 2012, 10

[18] Sigot, L.; Ducom, G.; Germain, P. Microporous Mesoporous Mater. 2015, 213, 118-124.

[19] Matsui, T.; Imamura, S. Bioresour. Technol. 2010, 101 (1 SUPPL.), S29-S32.

[20] Nam, S.; Namkoong, W.; Kang, J.-H.; Park, J.K.; Lee, N. Waste Manag. 2013, 33 (10), 2091-2098.

[21] Ajhar, M.; Travesset, M.; Yüce, S.; Melin, T. Bioresour. Technol. 2010, 101 (9), 2913-2923.

[22] Dewil, R.; Appels, L.; Baeyens, J. Energy Convers. Manag. 2006, 47 (13-14), 1711-1722.

[23] Abatzoglou, N.; Boivin, S. Biofuels, Bioprod. Biorefining 2009, 6(3), 42-71.

[24] Accettola, F.; Guebitz, G. M.; Schoeftner, R. Clean Technol. Environ. Policy 2008, 10 (2), 211-218. 